\title{
Skp1 Dimerization Conceals its F-box Protein Binding Site
}

Hyun W. Kim ${ }^{1, \ddagger}$, Alexander Eletsky ${ }^{2, \ddagger}$, Karen J. Gonzalez ${ }^{3}$, Hanke van der Wel ${ }^{1}$, Eva-Maria Strauch ${ }^{3}$, James H. Prestegard ${ }^{1,2}$, and Christopher M. West ${ }^{1,2,4, *}$

${ }^{1}$ Dept. of Biochemistry and Molecular Biology, ${ }^{2}$ Complex Carbohydrate Research Center, ${ }^{3}$ Dept. of Pharmaceutical and Biomedical Sciences, ${ }^{4}$ Center for Tropical and Emerging Global Diseases, University of Georgia, Athens, GA 30602 USA

$\$$ These authors contributed equally to this work.

\begin{abstract}
Skp1 is an adapter that links F-box proteins to cullin-1 in the Skp1/cullin-1/F-box (SCF) protein family of E3 ubiquitin ligases that targets specific proteins for polyubiquitination and subsequent protein degradation. Skp1 from the amoebozoan Dictyostelium forms a stable homodimer in vitro with a $K_{\mathrm{d}}$ of 2.5 $\mu \mathrm{M}$ as determined by sedimentation velocity studies, yet is monomeric in crystal complexes with F-box proteins. To investigate the molecular basis for the difference, we determined the solution NMR structure of a doubly truncated $\operatorname{Skp} 1$ homodimer $(\operatorname{Skp} 1 \Delta \Delta)$. The solution structure of $\operatorname{Skp} 1 \Delta \Delta$ dimer reveals a 2-fold symmetry with an interface that buries $\sim 750 \AA^{2}$ of predominantly hydrophobic surface. The dimer interface overlaps with subsite- 1 of the F-box interaction area, explaining why only the Skp1 monomer binds F-box proteins (FBPs). To confirm the model, Rosetta was used to predict amino acid substitutions that might disrupt the dimer interface, and the F97E substitution was chosen to potentially minimize interference with F-box interactions. A nearly full-length version of Skp1 with this substitution (Skp1 $\triangle$ F97E) behaved as a stable monomer at concentrations up to $500 \mu \mathrm{M}$ and actively bound a model FBP, mammalian Fbs1, which suggests that the dimeric state is not required for Skp1 to carry out a basic biochemical function. Finally, Skp1 $\Delta$ F97E is expected to serve as a monomer model for high-resolution NMR studies previously hindered by dimerization.
\end{abstract}




\section{INTRODUCTION}

The Skp1/cullin-1/F-box (SCF) protein family of E3 ubiquitin ligases is an important mediator of protein turnover in yeast/fungi, higher plants, and animals, owing to the role of polyubiquitination in serving as a signal for recognition and degradation in the 26S-proteasome. Evidence supports the importance of the SCF complex in the protist kingdom as well, ${ }^{1}$ where a novel posttranslational modification has been discovered in Skp1 orthologs from groups as diverse as amoebozoa (Dictyostelium discoideum), apicomplexans (Toxoplasma gondii), and oomycetes (Pythium ultimum). ${ }^{2}$ Protist Skp1 is subject, in the presence of sufficient $\mathrm{O}_{2}$ and $\alpha$-ketoglutarate, to hydroxylation of a Pro-residue that lies on the backside of subsite-2 of the F-box binding domain of Skp1. Once Skp1 is hydroxylated, the hydroxyproline (Hyp) residue is recognized and glycosylated by a series of glycosyltransferases, resulting in the assembly of a canonical pentasaccharide. Mutational studies show that both hydroxylation and full glycosylation are required for optimal $\mathrm{O}_{2}$-sensing in Dictyostelium and Toxoplasma. ${ }^{1,3}$ Biophysical and computational studies have generated a model by which the relatively organized structure of the pentasaccharide organizes the surrounding intrinsically disordered region of Dictyostelium Skp1 in such a way as to be more conducive to binding the F-box domain of FBPs, ${ }^{4}$ and recent studies indicate that this model is also relevant to Skp1 from Toxoplasma. ${ }^{3}$ Confirmatory biophysical studies using NMR are hampered by the dimeric state of glycosylated Skp1 (GGFGGn-Skp1) because of its relatively large size, 324 amino acids.

Recombinant guinea pig Skp1, whose sequence is identical across mammals, was previously reported to dimerize with a $K_{\mathrm{d}}$ of $1.1 \mu \mathrm{M}{ }^{5}$ This value is significantly below the estimated concentration of Skp1 (a.k.a. OCP2) in the inner ear tissues $(2 \mathrm{mM})$ where Skp1/OCP-2 was initially characterized, suggesting that dimerization might influence Skp1 activity in cells. Studies of Dictyostelium Skp1, where small angle X-ray scattering, gel filtration, and NMR studies confirmed its dimeric status at higher concentrations, indicate that glycosylation modestly inhibits dimerization. ${ }^{6}$ We sought to investigate the significance of Skp1 dimerization by mapping its dimer interface. The structure of Skp1 from mammals, yeast and higher plants is known when it is bound to F-box proteins. ${ }^{7,8}$ In contrast to the extensive sequence variations of Fbox domains, the sequence and structure of Skp1 in these complexes is highly conserved. However, free Skp1 has defied structural characterization, potentially because of intrinsically disordered regions (including its C-terminal region that contributes to F-box domain recognition) that interfere with the formation of crystals for X-ray crystallography. At the same time, the Skp1 homodimer is too large for solution NMR studies without resorting to ${ }^{2} \mathrm{H}$-isotope labeling. We have found that Dictyostelium Skp1A remains a dimer in the absence of both an internal disordered region that was originally removed to allow crystallization with F-box proteins, ${ }^{7}$ and the predominantly disordered region that comprises the C-terminal subsite- 2 of the F-box binding region. The doubly truncated $\operatorname{Skp} 1 \Delta \Delta$ dimer variant $(2 \times 118$ aa $)$ was sufficiently small to pursue high-resolution solution NMR structure determination using uniform ${ }^{15} \mathrm{~N}$ - and ${ }^{13} \mathrm{C}$-isotope labeling. We found that the homodimer interface overlaps with the F-box binding interface and confirmed the finding by Rosetta-guided mutagenesis, and discuss the implications for Skp1 function and future studies on its posttranslational regulation.

\section{MATERIALS AND METHODS}

Expression Plasmids. The E. coli expression plasmid pET19b-Skp1A $\Delta \Delta$ was derived from pET19bSkp1 $\mathrm{A}^{9}$ by site-directed mutagenesis, in which primers designed to bridge the deleted sequence as described in Figure S1C were used in a PCR reaction with Q5 ${ }^{\circledR}$ High-Fidelity DNA Polymerase (New England Biolabs) to amplify the modified vector. After treatment with DpnI to destroy the original vector, the sample was cloned into E. coli strain BL21-Gold(DE3).

For improved recovery and purification of Skp1, the Dictyostelium Skp1A coding sequence was codon optimized for expression in E. coli, and appended with an N-terminal His ${ }_{6}$-tag which, when excised by treatment with TEV protease, yielded the native sequence with an N-terminus of SMSL-, compared to the $\mathrm{N}$-terminal SL- that occurs natively after removal of the start Met. ${ }^{10}$ The cDNA (Figure S1A) was synthesized and provided in pUC57 by GenScript, excised using NcoI and BamHI, and ligated into the NcoI and BamHI restriction sites of pET19b, yielding pET19b-His ${ }_{6}$ DdSkp1A-optim. A second cDNA in 
which 12 internal amino acids (SPQGDDKKDEKR) were replaced with GGSG (Figure S1B) was synthesized and similarly ligated into pET19B yielding pET19b-His 6 DdSkp1A $\Delta$ Loop-optim. This plasmid was modified to generate an F97E point mutation by site-directed mutagenesis, in which the indicated primers were used in a PCR reaction to amplify the modified vector as above.

Expression and Purification of Skp1 constructs. Skp1 and Skp1 $\Delta \Delta$, which each lacked an affinity tag to ensure native-like behavior, were purified from $E$. coli to near homogeneity under non-denaturing conditions (DEAE, phenyl, Q and S200 Superdex columns) as described previously. ${ }^{6}$ Sample purity and integrity was assessed by SDS-PAGE and Coomassie blue staining to be $>90 \%$.

E. coli cells expressing $\mathrm{His}_{6} \mathrm{Skp} 1 \Delta$ or $\mathrm{His}_{6} \mathrm{Skp} 1 \Delta \mathrm{F} 97 \mathrm{E}$ were incubated at $37^{\circ} \mathrm{C}$ in $2 \times 1 \mathrm{~L}$ of Terrific Broth medium in the presence of $100 \mu \mathrm{g} / \mathrm{ml}$ ampicillin. At an $\mathrm{OD}_{600}$ of 0.6 , protein expression was induced by addition of $125 \mu \mathrm{M}$ isopropyl 1-thio- $\beta$-D-galactopyranoside (IPTG) at $20{ }^{\circ} \mathrm{C}$. After $12-16 \mathrm{~h}$, bacteria were collected by centrifugation at $5000 \times \mathrm{g}$ for $10 \mathrm{~min}$ and resuspended in $50 \mathrm{mM} \mathrm{Na}{ }^{+} / \mathrm{K}^{+}$phosphate $(\mathrm{pH}$ 7.8), $300 \mathrm{mM} \mathrm{NaCl}, 5 \mu \mathrm{g} / \mathrm{ml}$ aprotinin, $5 \mu \mathrm{g} / \mathrm{ml}$ leupeptin at $4{ }^{\circ} \mathrm{C}$. Cells were lysed using a probe sonicator (model 500, Thermo Fisher Scientific) for a total sonication time of $5 \mathrm{~min}$. The lysate was centrifuged at $25,000 \times g$ for $45 \mathrm{~min}$ at $4{ }^{\circ} \mathrm{C}$, and the supernatant was immediately applied to a 1.5 -ml column of $\mathrm{Co}^{2+}$ Talon resin (Clontech) pre-equilibrated at $4{ }^{\circ} \mathrm{C}$ in the buffer described above. The column was washed successively with the same buffer supplemented with either $1 \mathrm{M} \mathrm{NaCl}, 10 \%$ glycerol, or $5 \mathrm{mM}$ imidazole. Protein was eluted with buffer containing $300 \mathrm{mM}$ imidazole, and dialyzed against $50 \mathrm{mM}$ Tris- $\mathrm{HCl}(\mathrm{pH}$ 8.0), $300 \mathrm{mM} \mathrm{NaCl}, 1 \mathrm{mM}$ EDTA, $2 \mathrm{mM} \beta$-mercaptoethanol. The sample was incubated overnight at 22 ${ }^{\circ} \mathrm{C}$ with His ${ }_{6} \mathrm{TEV}$ protease to cleave the His ${ }_{6}$-tag from Skp1, and the sample was re-applied to the Talon resin. The flow-through was concentrated to $1.5 \mathrm{ml}$ using a spin concentrator (Amicon) with a $3 \mathrm{kDa}$ molecular weight cut-off. The concentrated sample was further purified over a Superdex $200 \mathrm{Hi}-\mathrm{load}$ 16/60 gel filtration column (GE Healthcare) pre-equilibrated with $20 \mathrm{mM}$ potassium phosphate $(\mathrm{pH} 7.4), 50 \mathrm{mM}$ $\mathrm{KCl}$, and $0.5 \mathrm{mM}$ TCEP. The sample was estimated to be $>95 \%$ pure by SDS-PAGE and staining with Coomassie blue.

Stable isotope labeled $\operatorname{Skp} 1 \Delta \Delta$ and $\mathrm{His}_{6} \operatorname{Skp} 1 \Delta \mathrm{F} 97 \mathrm{E}$ were prepared by expression in E. coli in the presence of isotope enriched minimal media as previously described. ${ }^{9}$ His $_{6}$ Skp $1 \Delta$ F97E was uniformly enriched with ${ }^{15} \mathrm{~N}$, and $\operatorname{Skp} 1 \Delta \Delta$ was labeled with ${ }^{15} \mathrm{~N}$ and ${ }^{13} \mathrm{C}$. The final Skp1 $\Delta \Delta$ NMR sample $(105 \mu 1$ in a 3-mm Shigemi tube) contained a 1:1 mixture of ${ }^{15} \mathrm{~N},{ }^{13} \mathrm{C}$-Skp1 $\Delta \Delta$ and natural abundance $\operatorname{Skp} 1 \Delta \Delta$ at $\sim 1.0$ $\mathrm{mM}$ concentration in $20 \mathrm{mM}$ MES-NaOH (pH 6.0), $50 \mathrm{mM} \mathrm{NaCl}, 5 \mathrm{mM}$ dithiothreitol, $0.05 \% \mathrm{NaN}_{3} .{ }^{15} \mathrm{~N}-$ labeled Skp1 $\Delta$ F97E NMR samples $(300 \mu \mathrm{l}$ in 5-mm Shigemi tubes) were prepared at concentrations of 100 $\mu \mathrm{M}$ and $500 \mu \mathrm{M}$ in the same buffer. All NMR samples contained $10 \% \mathrm{D}_{2} \mathrm{O}$ for spectrometer lock.

Analytical Ultracentrifugation. Protein was quantified based on molar absorptivity calculated from the protein sequence using ProtParam. ${ }^{11}$ Samples were loaded into 12-mm double-sector Epon centerpieces equipped with quartz windows and equilibrated for $2 \mathrm{~h}$ at $20^{\circ} \mathrm{C}$ in an An60 Ti rotor. Sedimentation velocity data were collected using an Optima XLA analytical ultracentrifuge (Beckman Coulter) at 50,000 rpm at $20^{\circ} \mathrm{C}$. Data were recorded with absorbance optics at $280 \mathrm{~nm}, 230 \mathrm{~nm}$ or $215 \mathrm{~nm}$ in radial step sizes of 0.003 $\mathrm{cm}$. SEDNTERP ${ }^{12}$ was used to model the partial specific volume as well as the density and viscosity of the buffer. SEDFIT ${ }^{13}$ was used to analyze sedimentation data. All data were modeled as continuous $c(s)$ distributions and were fit using baseline, meniscus, frictional coefficient, and systematic time-invariant and radial-invariant noise. Predicted sedimentation coefficient (s) values for Skp1 monomer and dimer states were calculated using HYDROPRO ${ }^{14}$ with a homology model generated on the ROBETTA server. ${ }^{15}$ Data fit and $c(s)$ plots were generated using GUSSI. ${ }^{16}$ Weight-averaged $\mathrm{S}$ values $\left(\mathrm{S}_{\mathrm{w}}\right)$ at each concentration were determined by integrating $c(s)$ distributions. Constructed $\mathrm{S}_{\mathrm{w}}$ isotherms were fitted with a $\mathrm{A}+\mathrm{A} \rightleftharpoons \mathrm{AA}$ selfassociation model using SEDPHAT. ${ }^{17}$

NMR Spectroscopy and Structure Determination of Skp1 $\Delta \Delta$. NMR spectra for $\operatorname{Skp} 1 \Delta \Delta$ were acquired at $35^{\circ} \mathrm{C}$ using a Bruker AVANCE NEO $800 \mathrm{MHz}$ spectrometer equipped with a 5-mm cryogenic TCI ${ }^{1} \mathrm{H}\left\{{ }^{13} \mathrm{C},{ }^{15} \mathrm{~N}\right\}$ probe, and an Agilent VNMRS $600 \mathrm{MHz}$ spectrometer equipped with a 3-mm cryogenic 
${ }^{1} \mathrm{H}\left\{{ }^{13} \mathrm{C},{ }^{15} \mathrm{~N}\right\}$ probe. NMR spectra for $100 \mu \mathrm{M}$ and $500 \mu \mathrm{M}$ Skp1 $\Delta \mathrm{F} 97 \mathrm{E}$ samples were acquired using a Bruker AVANCE NEO $900 \mathrm{MHz}$ spectrometer equipped with a 5-mm cryogenic TXO ${ }^{13} \mathrm{C},{ }^{15} \mathrm{~N}\left\{{ }^{1} \mathrm{H}\right\}$ probe, and the $600 \mathrm{MHz}$ spectrometer equipped with a 5-mm cryogenic ${ }^{1} \mathrm{H}\left\{{ }^{13} \mathrm{C},{ }^{15} \mathrm{~N}\right\}$ probe. The acquired NMR spectra are summarized in Table S1. NOE mixing times were $70 \mathrm{~ms}$ for ${ }^{13} \mathrm{C} /{ }^{15} \mathrm{~N}$-edited $\left[{ }^{1} \mathrm{H},{ }^{1} \mathrm{H}\right]$-NOESY and $120 \mathrm{~ms}$ for ${ }^{13} \mathrm{C} /{ }^{15} \mathrm{~N}$-filtered ${ }^{13} \mathrm{C} /{ }^{15} \mathrm{~N}$-edited $\left[{ }^{1} \mathrm{H},{ }^{1} \mathrm{H}\right]$-NOESY experiments. Fourier transform was performed with TopSpin (Bruker BioSpin) for Bruker NMR data, and NMRPipe ${ }^{18}$ for Varian NMR data. ${ }^{1} \mathrm{H}$ chemical shifts were referenced relative to 4,4-dimethyl-4-silapentane-1-sulfonic acid (DSS), and ${ }^{13} \mathrm{C}$ and ${ }^{15} \mathrm{~N}$ chemical shifts were referenced indirectly via gyromagnetic ratios. 2D and 3D NMR spectra were analyzed using CARA. ${ }^{19}$

Relaxation delays were $0.1,0.2,0.3,0.4,0.7,1.0,1.5$, and 2.0 seconds in $1 \mathrm{D}$ proton-detected ${ }^{15} \mathrm{~N} \mathrm{~T}_{1}$ experiments, and 10, 30, 50, 70,90,110,130, 150 and $170 \mathrm{~ms}$ in $1 \mathrm{D}$ proton-detected ${ }^{15} \mathrm{~N} \mathrm{~T}_{2}$ experiments acquired for the $500 \mu \mathrm{M}$ Skp1 $\Delta \mathrm{F} 97 \mathrm{E}$ sample. $1 \mathrm{D}^{15} \mathrm{~N} \mathrm{~T}_{1} / \mathrm{T}_{2}$ relaxation spectra were processed and analyzed with VnmrJ v4.2 (Agilent Inc). Macro "tc" (wiki.nesg.org) was used to integrate the regions between ${ }^{1} \mathrm{H}$ chemical shifts of 8.8 and $9.9 \mathrm{ppm}$, determine average ${ }^{15} \mathrm{~N} \mathrm{~T}_{1}$ and $\mathrm{T}_{2}$ relaxation times via exponential fitting, and calculate global rotational correlation time $\tau_{\mathrm{c}}$.

Sequence-specific backbone and side-chain resonance assignments for $\operatorname{Skp} 1 \Delta \Delta$ were derived using CARA based on existing resonance assignments of full-length Skp1. ${ }^{9}$ Structure calculation of the $\operatorname{Skp} 1 \Delta \Delta$ homodimer was performed using CYANA ${ }^{20}$ based on ${ }^{1} \mathrm{H}-{ }^{1} \mathrm{H}$ upper distance constraints derived from ${ }^{13} \mathrm{C} /{ }^{15} \mathrm{~N}$-edited $\left[{ }^{1} \mathrm{H},{ }^{1} \mathrm{H}\right]$-NOESY, as well as backbone $\varphi$ and $\psi$ and side-chain $\chi_{1}$ dihedral angle restraints from TALOS-N. ${ }^{21}$ Automated NOESY peak assignment was performed initially with CYANA, with 22 manually assigned intermolecular $5 \AA^{1}{ }^{1} \mathrm{H}-{ }^{1} \mathrm{H}$ upper distance constraints (Table S2) applied after cycle 1 of simulated annealing. These intermolecular ${ }^{1} \mathrm{H}-{ }^{1} \mathrm{H}$ upper distance constraints were derived from selected strong peaks in a ${ }^{13} \mathrm{C} /{ }^{15} \mathrm{~N}$-filtered ${ }^{13} \mathrm{C} /{ }^{15} \mathrm{~N}$-edited $\left[{ }^{1} \mathrm{H},{ }^{1} \mathrm{H}\right]$-NOESY spectrum. Only those peaks that could be unambiguously assigned and could not be explained by intramolecular contacts were chosen. After several rounds of iterative refinement of NOE peak assignments and calibration of distance constraints, the final structure calculation was performed with CYANA. Stereospecific resonance assignment of methylene proton spins and methyl groups of Leu and Val residues were obtained with the GLOMSA module of CYANA. Out of 100 calculated conformers, 20 conformers with the lowest target function values were selected for subsequent refinement in explicit water bath using the program $\mathrm{CNS}^{22}$ with upper distance constraints relaxed by $5 \%$. The structure statistics are outlined in Table 1.

Predicted rotational correlation time $\tau_{c}$ was calculated for $\operatorname{Skp} 1 \Delta \Delta$ and $\operatorname{Skp} 1 \Delta \mathrm{F} 97 \mathrm{E}$ using HYDRONMR, ${ }^{23}$ assuming water viscosity as $0.0072 \mathrm{cP}$ at $35^{\circ} \mathrm{C}$. The lowest energy conformer of $\operatorname{Skp} 1 \Delta \Delta$ NMR ensemble was used, and only the first chain was used to calculate $\tau_{\mathrm{c}}$ of a hypothetical $\operatorname{Skp} 1 \Delta \Delta$. Homology model of Skp1 $\Delta$ F97E monomer for $\tau_{c}$ calculation was generated with SWISS-MODEL based on X-ray structure of human Skp1 (PDB ID 3L2O) as a template. A hypothetical dimer model of Skp1 $\Delta$ F97E was then produced by structural alignment of individual subunits to those of $\operatorname{Skp} 1 \Delta \Delta$ dimer in Chimera (http://www.rbvi.ucsf.edu/chimera) ${ }^{24}$ followed by adjustment of backbone dihedral angles to eliminate clashes in the C-terminal region and energy minimization.

Analysis of the Dimer Interface. Computational investigation of the dimer interface was performed using the conformer with the lowest CYANA target function of the initial NMR structures of Skp1 $\Delta \Delta$. To prevent inaccurate predictions due to small clashes in the structure, the protein was prepared using the standard Rosetta optimization protocol, "FastRelax". ${ }^{25,26}$ Briefly, five cycles of rotamer packing and minimization were carried out, ramping up the repulsive weight in the scoring function within each cycle. After three rounds of symmetrical FastRelax with atom-atom pair distance constraints, the quality of the generated models was validated with the Molprobity web service. ${ }^{27}$ The lowest scoring structure based on the Rosetta energy score and the Molprobity score was selected for mutational analysis.

To identify mutations that could disrupt the Skp1 dimerization, an all amino acids-scanning mutagenesis was carried out across the homodimer interface in silico. The "flex ddG" protocol implemented in RosettaScripts ${ }^{28,29}$ was used to model and predict the effect of the mutations on the binding free energy 
of the complex. All parameters in the protocol were set up according to the default values described previously. ${ }^{28}$ Overall, the flex ddG method takes advantage of the Rosetta backrub approach ${ }^{30}$ to sample side-chain and backbone conformational changes around the mutated position. Once the backrub ensembles are generated, the structures are optimized by sidechain repacking and torsion minimization. The interface $\Delta \Delta \mathrm{G}$ score corresponds to the average difference in binding free energy between the mutant structure and the wild-type complex. Stabilizing mutations are defined as those with interface $\Delta \Delta \mathrm{G}$ scores $<-1.0$ Rosetta energy units (REU), while destabilizing mutations are assigned to interface $\Delta \Delta \mathrm{G}$ scores $>1.0{ }^{28}$

To determine which dimer-destabilizing substitutions do not perturb the stability of the individual monomers, the change in the total free energy of the monomer was estimated for all mutations. This analysis was performed with the current state-of-the-art Rosetta $\Delta \Delta \mathrm{G}$ protocol, "cartesian_ddg". ${ }^{31}$ Prior to the simulations, the refined wild-type monomer was relaxed in Cartesian space, constraining backbone and sidechain coordinates. The model with the lowest Rosetta score was then used as input for the cartesian_ddg protocol. Within the cartesian_ddg application, the protein was relaxed again in the Cartesian space, allowing movement of only the backbone and sidechains around the mutated position. ${ }^{31}$ All parameters in the method were configured as previously described. ${ }^{31}$ The total $\Delta \Delta \mathrm{G}$ score was finally considered as the difference in the total $\Delta \Delta \mathrm{G}$ between the mutant and the wild-type monomer, multiplied by an energy scaling factor of 1.0/2.94. As above, stabilizing mutations correspond to total $\Delta \Delta \mathrm{G}$ scores $<-1.0$, and destabilizing mutations refer to total $\Delta \Delta \mathrm{G}$ scores $>1.0$.

All Rosetta commands for this report were run with the same Rosetta static executable (RosettaCommons/main.git2019-03-07, version 4ab48a76160c888257155619edb9817845bd8a67). The protocols previously described can be found at Supplementary information- Scripts.

Analytical Gel Filtration. Skp1 $\Delta$ and Skp1 $\Delta$ F97E with or without Fbs1 at a limiting concentration were subjected to Superdex 200 PC 3.2/30 gel filtration analysis using a Pharmacia SMARTSystem HPLC as previously described. ${ }^{6}$

\section{RESULTS}

Characterization of the Skp1 Dimer. Sedimentation velocity experiments were conducted on Dictyostelium Skp1A (Skp1) that was recombinantly expressed without a peptide tag in E. coli. Over a concentration range of $0.5-45 \mu \mathrm{M}$, the samples yielded peaks at $1.8 \mathrm{~S}$ and $2.7 \mathrm{~S}$ (Figure 1A), values which are slightly less than the predicted S-values for monomer and dimer forms, $1.9 \mathrm{~S}$ and $2.8 \mathrm{~S}$. The homology model used for predicting S-values assumed that the C-terminal region of Skp1 is organized as $\alpha$-helices as occurs in complexes with F-box proteins. However, the C-terminal region of free Skp1 is predominantly disordered based on previous NMR studies, ${ }^{9}$ which is expected to cause Skp1 to sediment more slowly and would explain the slight discrepancy between the observed and predicted S-values. The separate peaks indicate that interconversion between monomer and dimer states is slow relative to the time scale of sedimentation. A Skp1 dimer binding isotherm constructed using weighted S-values from across the concentration range yielded a dissociation constant for the Skp1 dimer of $2.5 \mu \mathrm{M}$ (Figure 1B).

Skp1 has resisted crystallization and the large size of the full-length homodimer (324 amino acids) inhibited structure determination by NMR. To initiate mapping of the dimer interface, we examined a truncated Skp1 variant, Skp1 $\Delta \Delta$, which lacks the mainly disordered C-terminal F-box binding domain and an internal disordered loop that is frequently removed for Skp1/FBP crystallization (Figure 2A). We demonstrated that $\operatorname{Skp} 1 \Delta \Delta(118 \times 2$ amino acids $)$ still forms a stable homodimer based on sedimentation velocity studies, which yielded an S-value of 1.9, in agreement with the 1.9 S-value predicted by HYDROPRO (Figure S2). Also, a 2D $\left[{ }^{15} \mathrm{~N},{ }^{1} \mathrm{H}\right] \mathrm{HSQC}$ spectrum of $\mathrm{Skp} 1 \Delta \Delta$ correlated well with 2D $\left[{ }^{15} \mathrm{~N},{ }^{1} \mathrm{H}\right]$ TROSY of full-length Skp1 (data not shown), indicating that truncations in $\operatorname{Skp} 1 \Delta \Delta$ do not perturb the overall structure.

Solution NMR Structure of Skp1 $\Delta \Delta$. Using a suite of standard NMR experiments (Table S1), we obtained complete sequence-specific assignments of backbone and side-chain ${ }^{1} \mathrm{H},{ }^{15} \mathrm{~N}$ and ${ }^{13} \mathrm{C}$ resonances 
of $\operatorname{Skp} 1 \Delta \Delta$ (Table 1; Figure S3). These resonance assignments allowed us to pursue structure calculations based on ${ }^{1} \mathrm{H}-{ }^{1} \mathrm{H}$ distance constraints derived from $3 \mathrm{D}{ }^{15} \mathrm{~N}$ - and ${ }^{13} \mathrm{C}$-edited $\left[{ }^{1} \mathrm{H},{ }^{1} \mathrm{H}\right]$ NOESY spectrum. To ensure proper modeling of the subunit interaction, we applied weak intermolecular distance ${ }^{1} \mathrm{H}-{ }^{1} \mathrm{H}$ constraints (Table S2) derived from NOE peaks identified in a separate ${ }^{13} \mathrm{C} /{ }^{15} \mathrm{~N}$-filtered and ${ }^{13} \mathrm{C}$-edited $\left[{ }^{1} \mathrm{H},{ }^{1} \mathrm{H}\right]$ NOESY spectrum recorded with a sample of mixed $\mathrm{U}-{ }^{15} \mathrm{~N},{ }^{13} \mathrm{C}$-labeled and natural abundance $\operatorname{Skp} 1 \Delta \Delta$. Representative fragments of NOESY spectra are shown in Figure S4. Full attenuation of intrachain NOE cross-peaks was not achieved in the ${ }^{13} \mathrm{C} /{ }^{15} \mathrm{~N}$-filtered spectrum (right strip in Figure S4) because of incomplete isotope incorporation ( $85 \%)$. However, comparison with the corresponding strip from the NOESY spectrum without isotope filtering (strip on the left) allowed us to distinguish between peaks of comparable intensity (inter-chain) and peaks with significantly reduced intensity in the filtered set (intrachain).

We obtained a high-quality solution NMR structure of $\operatorname{Skp} 1 \Delta \Delta$ (Table 1; Figure 2). A ribbon diagram of the best scoring structure of the top 20 conformers (Figure 2B) is shown in Figure 2C. The structure features a semi-parallel orientation of subunits with respect to their $\mathrm{N}$ - and $\mathrm{C}$-termini, in contrast to the previously hypothesized dimerization model from SAXS analysis. ${ }^{6}$ The dimer interface is organized as a four-helix bundle, with symmetrical packing contributions from residues of helices $5 \& 6$ of each chain (Figure S5) as identified using PISA. ${ }^{36}$ The interface buries $\sim 743 \AA^{2}$ of predominantly hydrophobic surface whose participating amino acids are labeled in Figure 2D. Superimposition of the corresponding C $\alpha$ atoms with human Skp1 from a crystal structure in complex with the human FBP $\beta$ TRCP revealed an RMSD of $1.1 \AA$ (Figure S6), indicating that the structure of amino acids 1-125 of free Skp1 changes little when complexed as a monomer with FBPs. Furthermore, the homodimer interface involves the previously described subsite- 1 of the binding site for F-box domains. ${ }^{7}$ The physical overlap (compare Figures 2E, F) was quantified by modeling the F-box domain of human FBXW7 from a crystal structure with human Skp1, with $\operatorname{Skp} 1 \Delta \Delta$. This revealed a $\sim 650 \AA^{2}$ overlap of the homodimer and heterodimer interfaces, in the region of helices 5 and 6, and explains why only the Skp1 monomer is found in complexes with FBPs.

Conservation of the Dimer Interface. The two $\alpha$-helices contributing to the homodimer interface, extending from L96 to I123, are highly conserved throughout phylogeny. Furthermore, each dimer contact residue except K117 is almost perfectly conserved from stramenopiles to humans (Figure S8), and the region is immediately surrounded by Gly or Pro residues and length variations (indels), indicating that this region represents a functional unit under selective pressure to remain intact. This is consistent with the finding that human Skp1 also dimerizes in this concentration range. ${ }^{5}$

Computationally-Guided Selection of a Skp1 Monomer Mutant. To test the dimer structure model, we searched for point mutations of interface amino acids that might destabilize the dimer. An initial alaninescanning mutagenesis calculation suggested Phe97 Leu101, and Ile123 as potential destabilizing positions based on a weakening of the binding free energy of the complex (interface $\Delta \Delta \mathrm{G}$ score $>2$ ) (Figures $3 \mathrm{~A}$, 3B). All 20 amino acids were then substituted at each position to predict the effect of different side chains. Indeed, most substitutions at these 3 positions were destabilizing, and $85 \%$ of the variations at position 97 yielded interface $\Delta \Delta \mathrm{G}$ scores greater than 1.5. The mutations F97G, F97D and F97E showed the highest dimer-destabilizing effect, with interface $\Delta \Delta \mathrm{G}$ scores of 5.41, 5.23 and 4.87, respectively (Figure 3C).

To determine whether the dimer-destabilizing mutations might affect monomer stability, the total monomer $\Delta \Delta \mathrm{G}$ was estimated for each substitution. Remarkably, most of the mutations at positions 97,101 , and 123 presented total $\Delta \Delta \mathrm{G}$ scores between 1 and -1 (Figure S7). In particular, the highly dimer destabilizing F97E substitution is predicted to have a neutral effect on monomer stability with its $\Delta \Delta \mathrm{G}$ score at 0.15 .

Based on the above analysis, the conserved Phe97 was changed to Glu in the nearly full length Skp1 $\Delta$ isoform. Glu was chosen over Asp to allow extension of the carboxyl group to provide better accessibility to solvent rather than clashing when binding an FBP. As predicted by the dimer interface model, Skp1 $\triangle$ F97E eluted as a monomer based on gel filtration and was predominantly a monomer by AUC at 100 $\mu \mathrm{M}$ (Figure 4A). A 2D [ $\left.{ }^{1} \mathrm{H},{ }^{15} \mathrm{~N}\right]$-HSQC spectrum recorded for a ${ }^{15} \mathrm{~N}$-labeled Skp1 $\Delta \mathrm{F} 97 \mathrm{E}$ sample exhibited 
peak dispersion consistent with a well-folded protein (Figure 4B). The peak pattern was comparable to that of wild-type Skp1 considering that there are a number of differences including an N-terminal SMextension, replacement of 12 amino acids with 4 different amino acids in the internal loop, and truncation after amino acid 125 (not shown). Based on average ${ }^{15} \mathrm{~N} \mathrm{~T}_{1}$ and $\mathrm{T}_{2}$ relaxation times measured for all ${ }^{1} \mathrm{H}$ amide resonances between 8.8 and $9.9 \mathrm{ppm}$ in a $500 \mu \mathrm{M}$ sample of Skp1 $\Delta \mathrm{F} 97 \mathrm{E}$, the effective rotational correlation time $\left(\tau_{\mathrm{c}}\right)$ was calculated at $9.4 \pm 0.5 \mathrm{~ns}$. This is close to the $10.9 \mathrm{~ns}$ value predicted for the monomer (Table 2), and contrasts with the previously reported $19.9 \pm 2.2$ ns value of the full-length protein. ${ }^{4}$ Thus, Skp1 $\triangle \mathrm{F} 97 \mathrm{E}$ remains predominantly monomeric even at high concentrations typical for solution NMR.

Skp1 $\triangle$ F97E is Binding Competent with a Model FBP. Phe97 is conserved as a Phe or Tyr in known Skp1s (Figure S8). Analysis of Skp1 in crystal structures of complexes with 3 different FBPs (Tir1, $\beta T R C P 1$, Fbs1) shows that, compared to the homodimer, Phe (or Tyr) resides in a different rotamer state with solvent exposure (not shown). This suggests that the F97E replacement will, though removing a favorable hydrophobic contact, not directly disrupt the FBP interaction. To test the functionality of Skp1 $\Delta$ F97E, we used a Superdex200 gel filtration column to examine the elution profile of Skp1 in the absence and presence of a heterologous FBP, guinea pig Fbs1. As previously described ${ }^{6}$ and replicated in Figure 4C, a mixture of Fbs 1 and Skp1 eluted prior to the elution positions of either protein alone. As shown in Figure $4 \mathrm{D}, \mathrm{Skp} 1 \Delta \mathrm{F} 97 \mathrm{E}$ exhibited similar behavior. In addition, Skp1 $\Delta \mathrm{F} 97 \mathrm{E}$ clearly eluted later than native Skp1, consistent with its monomeric character as described by AUC and its NMR-derived rotational correlation time. Thus Skp1(F97E) retained its FBP binding function, though a possible reduction in affinity is not excluded by this analysis.

\section{DISCUSSION}

Our findings confirm that dimerization is a highly conserved property of Skp1, based on similar dissociation constant values from organisms as phylogenetically distant as Dictyostelium and humans. Their measured $K_{\mathrm{d}}$ values range from 1.1 to $2.5 \mu \mathrm{M}$ under in vitro conditions, though actual affinities in the cell may vary. These values are similar to the predicted total monomer Skp1 concentration in a mammalian cell line, $\sim 2 \mu \mathrm{M} .^{37}$ The significance of dimerization is suggested by the exceptionally high degree of conservation of the contact residues (labeled D in Figure S8), and its ability to mask the hydrophobic character of this solvent exposed surface.

The Skp1 dimer interface occupies $\sim 740 \AA^{2}$ of predominantly hydrophobic surface, a substantial area that overlaps subsite-1 of its FBP binding site (Figure 2E). The corresponding region in human Skp1 (residues 99-130 in human vs. residues 93-124 in Dictyostelium Skp1, Figure S8) exhibited a paucity of NMR resonance assignments in a recent study of human $S k p 1,{ }^{38}$ indicating potential effects of dimerization in human Skp1. The homodimerization model was supported by the predicted effect of an amino acid substitution within the interface, F97E, to destabilize the interaction (Figure 4A) without unfolding the protein (Figure 4B). Indeed, monomeric Skp1 maintained its ability to bind a model FBP, Fbs1 (Figure 4C, D), and was also competent to be enzymatically hydroxylated and fully glycosylated in vitro (unpublished data). A further contribution to the dimer interface from beyond the truncation site at residue 125 seems unlikely, because previous studies indicated substantial disorder for this region in the free dimer. ${ }^{9}$

Based on the new structure, the dimer interface also contributes to subsite-1 of the F-box binding region of Skp1, which explains why Skp1 is a monomer in complexes with FBPs. ${ }^{8}$ Interestingly, 8 of the 13 alleles of Skp1 known to affect its function in budding and fission yeast have point mutations located on this region, ${ }^{39-43}$ raising the question of whether these mutations affect dimerization, FBP binding, or both. Since the Skp1/FBP interaction is very strong $\left(K_{\mathrm{d}}\right.$ for binding to the FBP Fbs1/OCP1 is ca. two orders of magnitude smaller than the homodimerization $\left.K_{\mathrm{d}}\right)^{44}$, and quantitative mass spectrometry indicates that Skp1 is not in great excess over FBPs in cells, ${ }^{37}$ the average concentration of Skp1 does not appear to be high enough to generate a substantial homodimer pool. However, if higher local concentrations occur in the cell, homodimerization might occur to protect Skp1 from interacting promiscuously with other macromolecules. 
Our ability to selectively perturb dimerization relative to Fbs1 binding using the F97E mutation might allow an investigation of this question in vivo; however, we cannot exclude the possibility that interaction with FBPs is quantitatively affected.

Chemical shift index analysis of assigned residues of free human ${ }^{38}$ and Dictyostelium ${ }^{9}$ Skp1s indicated that the overall secondary structure elements of the dimers were similar to one another and to human Skp1 in complexes with FBPs, except for the C-terminal F-box subsite-2 region (residues 126-162) which was predominantly disordered in free Skp1's. The current study of residues 1-125 extends to show that free Skp1 (dimer) assumes essentially the same structure as for human Skp1 bound to the FBP $\beta$ TRCP, with an RMSD for the corresponding $\mathrm{C} \alpha$ atoms of $1.1 \AA$ (Figure S6). Thus interactions with proteins including $\mathrm{Cul}^{8}{ }^{8}$ and Sgt $1,{ }^{45}$ whose crystallographically defined binding interfaces lie within this region but $\mathrm{N}$-terminal to the dimer interface (ca. residues 1-90), are likely to be unaffected by the dimer status of Skp1.

Owing to the semi-parallel arrangement of the monomers, the two C-termini of the $\operatorname{Skp} 1 \Delta \Delta$ dimer are close enough to one another that the missing C-terminal regions have the potential to influence one another in the native protein. The availability of a stable monomeric form of Skp1 will now allow a direct NMR analysis of full length Skpl and the consequences of its glycosylation, which has been postulated to influence the organization of F-box binding subsite- $2^{4,46}$ - the C-terminal region that was truncated to enable the dimer structure reported here.

\section{ASSOCIATED CONTENT}

\section{Supporting Information}

The Supplement PDF contains Tables S1-S2, Figures S1-S8, and supplemental methods.

\section{AUTHOR INFORMATION}

\section{Corresponding Author}

*E-mail: westcm@uga.edu

\section{Author Contributions}

HWK and AE conducted the experiments. HWK, AE and KJG performed calculations. AE, HWK, EMS, JHP and CMW advised on design and interpretation. HWK, AE and CMW wrote the initial manuscript draft, which was edited by all authors and finalized by CMW. All authors approved the final version. *These authors contributed equally.

\section{Funding Sources}

This research was supported by NIH R01-GM037539, NIH R01-AI140245, NIH R01-GM033225, NIH T32-GM107004, and a collaboration facilitated by the Resource for Integrated Glycotechnology, NIH P41GM103390. UCSF Chimera, which was utilized for some molecular graphics analyses, was developed by the Resource for Biocomputing, Visualization, and Informatics at the University of California, San Francisco, with support from NIH P41-GM103311.

\section{Notes}

The authors declare no competing financial interests.

\section{ACCESSION CODES}

Dictyostelium discoideum Skp1A sequence: UniProtKB/Swiss-Prot: P52285.1

Skp1 $\Delta \Delta$ dimer NMR structure statistics: PDB ID: 6V88, BMRB ID:30696

\section{ACKNOWLEDGMENT}

The authors thank John Glushka for NMR technical support. 


\section{ABBREVIATIONS}

AUC, analytical ultracentrifugation; FBP, F-box protein; HNOE, heteronuclear NOE; HSQC, heteronuclear single quantum coherence spectroscopy; NOESY, nuclear Overhauser enhancement spectroscopy; SCF, Skp1/cullin-1/F-box protein family of E3 ubiquitin ligases; Skp1 $\Delta$, Skp1 $\Delta$ internal loop; Skp1 $\Delta \Delta$, Skp1 $\Delta$ internal loop/ $\Delta \mathrm{C}$-terminus; TEV, tobacco etch virus

\section{REFERENCES}

1. West CM, Blader IJ (2015) Oxygen sensing by protozoans: How they catch their breath. Curr Opin Microbiol 26:41-47.

2. van der Wel H, Gas-Pascual E, West CM (2019) Skp1 isoforms are differentially modified by a dual function prolyl 4-hydroxylase/N-acetylglucosaminyltransferase in a plant pathogen. Glycobiology 29:705714.

3. Mandalasi M, Kim HW, Thieker D, Sheikh MO, Gas-Pascual E, Rahman K, Zhao P, Daniel N, van der Wel H, Ichikawa TH, Glushka JN, Wells L, Woods RJ, Wood ZA, West CM (2020) A glycogenin homolog controls Toxoplasma gondii growth via glycosylation of an E3 ubiquitin ligase. bioRxiv. https://www.biorxiv.org/content/10.1101/764241v2

4. Sheikh MO, Thieker D, Chalmers G, Schafer CM, Ishihara M, Azadi P, Woods RJ, Glushka JN, Bendiak B, Prestegard JH, West CM (2017) $\mathrm{O}_{2}$ sensing-associated glycosylation exposes the F-boxcombining site of the Dictyostelium Skp1 subunit in E3 ubiquitin ligases. J Biol Chem 292:18897-18915.

5. Henzl MT, Thalmann I, Thalmann R (1998) OCP2 exists as a dimer in the organ of Corti. Hear Res 126:37-46.

6. Sheikh MO, Schafer CM, Powell JT, Rodgers KK, Mooers BHM, West CM (2014) Glycosylation of Skp1 affects its conformation and promotes binding to a model F-box protein. Biochemistry 53:16571669.

7. Schulman BA, Carrano AC, Jeffrey PD, Bowen Z, Kinnucan ERE, Finnin MS, Elledge SJ, Harper JW, Pagano M, Pavietich NP (2000) Insights into SCF ubiquitin ligases from the structure of the Skp1-Skp2 complex. Nature 408:381-386

8. Zimmerman ES, Schulman BA, Zheng N (2010) Structural assembly of cullin-RING ubiquitin ligase complexes. Curr Opin Struc Biol 20:714-721.

9. Xu X, Eletsky A, Sheikh MO, Prestegard JH \& West CM (2018) Glycosylation promotes the random coil to helix transition in a region of a protist Skp1 associated with F-box binding. Biochemistry 57:51515.

10. West CM, Kozarov E, Teng-umnuay P (1997) The cytosolic glycoprotein FP21 of Dictyostelium discoideum is encoded by two genes resulting in a polymorphism at a single amino acid position. Gene 200:1-10.

11. Gasteiger E, Hoogland C, Gattiker A, Duvaud S, Wilkins MR, Appel RD, Bairoch A (2005) Protein identification and analysis tools on the ExPASy server. In: Walker JM (ed): The Proteomics Protocols Handbook, Humana Press. pp. 571-607.

12. Laue TM, Shah BD, Ridgeway TM, Pelletier SL (1992) Computer-aided interpretation of analytical 
sedimentation data for proteins. In: Harding SE, Rowe AJ, Horton J, editors. Analytical Ultracentrifugation in Biochemistry and Polymer Science. Cambridge: The Royal Society of Chemistry. pp. $90-125$.

13. Schuck P (2000) Size distribution analysis of macromolecules by sedimentation velocity ultracentrifugation and Lamm equation modeling. Biophysical J 78:1606-1619.

14. Ortega A, D. Amorós, J. Garcla de la Torre (2011) Prediction of hydrodynamic and other solution properties of rigid proteins from atomic- and residue-level models. Biophys J 101:892-898.

15. Kim DE, Chivian D, Baker D (2004) Protein structure prediction and analysis using the Robetta server. Nucleic Acid Res. 32(Web Server issue):W526-531.

16. Brautigam CA (2015) Calculations and publication-quality illustrations for analytical ultracentrifugation data. Meth Enzymol 562:109-133.

17. Schuck P (2003) On the analysis of protein self-association by sedimentation velocity analytical ultracentrifugation. Anal Biochem 320:104-124.

18. Delaglio F, Grzesiek S, Vuistere GW, Zhu G, Pfeifer J, Bax A (1995) NMRPipe: a multidimensional spectral processing system based on UNIX pipes. J. Biomol. NMR 6:277-293.

19. Keller, R. (2004) The Computer aided resonance assignment tutorial, CANTINA Verlag, Goldau.

20. Güntert P, Buchner, L (2015) Combined automated NOE assignment and structure calculation with CYANA. J. Biomol NMR 62:453-471.

21. Shen Y, Bax A (2013) Protein backbone and sidechain torsion angles predicted from NMR chemical shifts using artificial neural networks. J Biomol NMR 56:227-241.

22. Brunger AT, Adams PD, Clore GM, Gros P, Grosse-Kunstleve RW, Jiang JS, Kuszewski J, Nilges N, Pannu NS, Read RJ, Rice LM, Simonson T, Warren GL (1998) Crystallography \& NMR system (CNS), A new software suite for macromolecular structure determination. Acta Cryst 54:905-921.

23. García de la Torre J, Huertas ML, Carrasco B (2000) HYDRONMR: Prediction of NMR relaxation of globular proteins from atomic-level structures and hydrodynamic calculations. J Magnet Resonance 147:138-146.

24. Pettersen EF, Goddard TD, Huang CC, Couch GS, Greenblatt DM, Meng EC, Ferrin TE (2004) UCSF Chimera - a visualization system for exploratory research and analysis. J Comput Chem 25:16051612.

25. Tyka MD, Keedy DA, Andre I, Dimaio F, Song Y, Richardson DC, Richardson JS, Baker D (2011) Alternate states of proteins revealed by detailed energy landscape mapping. J Mol Biol 405:607-618.

26. Das R, Baker D. (2008) Macromolecular modeling with Rosetta. Annu Rev Biochem 77:363-382.

27. Chen VB, Arendall WB $3^{\text {rd }}$, Headd JJ, Keedy DA, Immormino RM, Kapral GJ, Murray LW, Richardson JS, Richardson DC (2010) MolProbity: all-atom structure validation for macromolecular crystallography. Acta Crystallogr Sec D Biol Crystallogr 66:12-21. 
28. Barlow KA, O Conchuir S, Thompson S, Suresh P, Lucas JE, Heinonen M, Kortemme T (2018) Flex ddG: Rosetta ensemble-based estimation of changes in protein-protein binding affinity upon mutation. $J$ Phys Chem B 122:5389-5399.

29. Fleishman SJ, Leaver-Fay A, Corn JE, Strauch EM, Khare SD, Koga N, Ashworth J, Murphy P, Richter F, Lemmon G, Meiler Jens, Baker D (2011) Rosettascripts: a scripting language interface to the Rosetta macromolecular modeling suite. PLoS One 6: e20161.

30. Smith CA, Kortemme T (2008) Backrub-like backbone simulation recapitulates natural protein conformational variability and improves mutant side-chain prediction. J Mol Biol 380:742-756.

31. Park H, Bradley P, Greisen P, Liu Y, Mulligan VK, Kim DE, Baker D, DiMaio F (2016) Simultaneous optimization of biomolecular energy functions on features from small molecules and macromolecules. J Chem Theory Comput 12: 6201-6212.

32. Bhattacharya A, Tejero R, and Montelione GT (2007) Evaluating protein structures determined by structural genomics consortia. Proteins 50:778-795.

33. Laskowski RA, Rullmannn JA, MacArthur MW, Kaptein R, and Thornton JM (1996) AQUA and PROCHECK-NMR: programs for checking the quality of protein structures solved by NMR. J Biomol NMR 8:477-486

34. Lovell SC, Davis IW, Arendall WB III, de Bakker PIW, Word JM, Prisant MG, Richardson JS, Richardson DC (2003) Structure validation by Calpha geometry: phi,psi and Cbeta deviation. Proteins 50:437-450.

35. Sippl MJ (1993) Recognition of errors in three-dimensional structures of proteins. Proteins 17:355362.

36. Krissinel E (2015) Stock-based detection of protein oligomeric states in jsPISA. Nuc Ac Res 43:W314-319.

37. Reitsma JM, Liu X, Reichermeier KM, Moradian A, Sweredoski MJ, Hess S, Deshaies RJ (2017) Composition and regulation of the cellular repertoire of SCF ubiquitin ligases. Cell 171:1326-1339.

38. Kachariya NN, Dantu SC, Kumar A (2016) Backbone and side chain assignments of human cell cycle regulatory protein S-phase kinase-associated protein 1. Biomol NMR Assign 10:351-355.

39. Bai C, Sen P, Hofmann K, Ma L, Goebl M, Harper JW, Elledge SJ (1996) SKP1 connects cell cycle regulators to the ubiquitin proteolysis machinery through a novel motif, the F-box. Cell 86:263-274.

40. Connelly C, Hieter P (1996) Budding yeast SKP1 encodes an evolutionarily conserved kinetochore protein required for cell cycle progression. Cell 86:275-285.

41. Beltrao P, Albanèse V, Kenner LR, Swaney DL, Burlingame A, Villén J, Lim WA, Fraser JS, Frydman J, Krogan NJ (2012) Systematic functional prioritization of protein posttranslational modifications. Cell 150:413-425.

42. Lehmann A, Katayama S, Harrison C, Dhut S, Kitamura K, McDonald N, Toda T (2004) Molecular interactions of fission yeast Skp1 and its role in the DNA damage checkpoint. Genes Cells 9:367-382. 
43. Leber V, Nans A, Singleton MR (2018) Structural basis for assembly of the CBF3 kinetochore complex. EMBO J 37:269-281.

44. Tan A, Tanner JJ, Henzl MT (2008) Energetics of OCP1-OCP2 complex formation. Biophys Chem 134:64-71.

45. Willhoft O, Kerr R, Patel D, Zhang W, Al-Jassar C, Daviter T, Millson SH, Thalassinos K, Vaughan CK (2017) The crystal structure of the Sgt1-Skp1 complex: the link between Hsp90 and both SCF E3 ubiquitin ligases and kinetochores. Sci Rep 7:41626.

46. West CM, Kim HW (2019) Nucleocytoplasmic O-glycosylation in protists. Curr Opin Struct Biol 56:204-212.

47. West CM, van der Wel H, Gaucher EA (2002) Complex glycosylation of Skp1 in Dictyostelium: implications for the modification of other eukaryotic cytoplasmic and nuclear proteins. Glycobiology 12:17R-27R. 
Table 1. Skp1 $\Delta \Delta$ dimer NMR structure statistics (PDB ID: 6V88, BMRB ID:30696)

\section{Completeness of resonance assignments ${ }^{\mathrm{a}}[\%]$}

Backbone/Side-chain

$100.0 / 100.0$

Conformation-restricting distance constraints ${ }^{b}$

Intra-residue $[\mathrm{i}=\mathrm{j}]$

696

Sequential $[|\mathrm{i}-\mathrm{j}|=1]$

1256

Medium range $[1<|\mathrm{i}-\mathrm{j}|<5]$

1360

Long range $[|\mathrm{i}-\mathrm{j}| \geq 5]$

1470

Total

4782

Intermolecular NOE constraints (included in above)

182

Dihedral angle constraints

406

NOE constraints per restrained residue (of those, long range)

CYANA target function $\left[\AA^{2}\right]$

Average number of distance constraint violations per conformer
$0.1-0.2 A$
9.25
$0.2-0.5 \AA$
2.2
$>0.5 \AA$
0

Average number of dihedral angle constraint violations per conformer $>10^{\circ}$

Average RMSD from mean coordinates $[\AA]$

0.1

backbone atoms ${ }^{c}$ (all)

heavy atoms ${ }^{c}$ (all)

Global quality scores ${ }^{\mathrm{c}}$ (raw / Z-score)

PROCHECK ${ }^{2}$ G-factor (phi-psi)

$0.16 / 0.94$

PROCHECK ${ }^{2}$ G-factor (all)

$0.14 / 0.83$

Molprobity ${ }^{3}$ clash score

$2.55 / 1.09$

ProsalI ${ }^{4}$

$0.74 / 0.37$

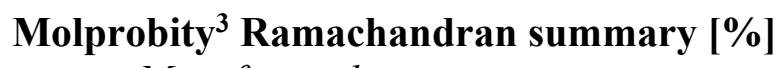

Most favored regions

98.7

Additionally allowed regions

1.3

Disallowed regions

0.0

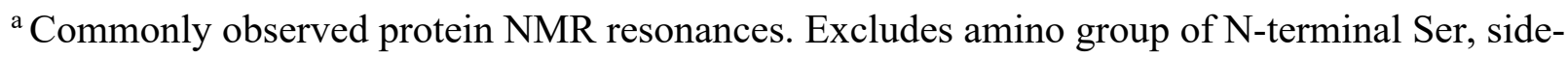
chain amino groups of Lys, side-chain guanidinium groups of Arg, carboxyl groups of Asp and Glu, thiol and hydroxyl ${ }^{1} \mathrm{H}$ of Cys, Ser, Thr and Tyr, and non-protonated aromatic ${ }^{13} \mathrm{C}$.

${ }^{\mathrm{b}}$ Calculated with Protein Structure Validation Software (PSVS 1.5; http://psvs.nesg.org/)

${ }^{\mathrm{c}}$ Ordered residue ranges: 3-34, 38-44, 46-64, 74-115

${ }^{1}$ Ref. 32

${ }^{2}$ Ref. 33

${ }^{3}$ Ref. 34

${ }^{4}$ Ref. 35 
bioRxiv preprint doi: https://doi.org/10.1101/764126; this version posted January 26, 2020. The copyright holder for this preprint (which was not certified by peer review) is the author/funder, who has granted bioRxiv a license to display the preprint in perpetuity. It is made available under aCC-BY-NC-ND 4.0 International license.

Table 2. Predicted and Experimental $\tau_{\mathrm{c}}$ for Skp1 isoforms at $35^{\circ} \mathrm{C}$

\begin{tabular}{|l|l|l|}
\hline & Predicted $^{\mathrm{a}} \tau_{\mathrm{c}}(\mathrm{ns})$, monomer/dimer & Experimental $\tau_{\mathrm{c}}(\mathrm{ns})$ \\
\hline Skp1 $\Delta \mathrm{F} 97 \mathrm{E}, 500 \mu \mathrm{M}$ & $10.9 / 19.6$ & $9.4 \pm 0.5$ \\
\hline Skp1(native), $850 \mu \mathrm{M}$ & Similar to above $^{\mathrm{b}}$ & $19.5 \pm 2.2^{\mathrm{b}}$ \\
\hline
\end{tabular}

${ }^{a}$ Predicted using HYDRONMR ${ }^{23}$

${ }^{\mathrm{b}}$ from Ref. 7 


\section{FIGURE LEGENDS}

Figure 1. Sedimentation velocity analysis of $D d \operatorname{Skp} 1$. (A) $c(s)$ distribution reveals concentration dependence of dimerization. The concentration range is depicted by a rainbow spectrum with the lowest concentration in red and the highest in purple. (B) An isotherm was constructed with weighted s-values $\left(\mathrm{S}_{\mathrm{w}}\right)$; the fitted model indicates a $K_{\mathrm{d}}$ of $2.5 \mu \mathrm{M}$. The color of each data point corresponds to the respective $c(s)$ distribution in panel A.

Figure 2. Structure of the Skp1 dimer. (A) Domain diagrams of the constructs examined. Note that versions derived from His $_{6} \mathrm{Skp} 1$ have a SerMet-extension beyond the native Ser- resulting from Met removal. See Figure S1 for details. (B) Superimposition of C $\alpha$-traces of 20 calculated conformers of $\operatorname{Skp} 1 \Delta \Delta$. (C) Ribbon representation of the lowest energy $\operatorname{Skp} 1 \Delta \Delta$ conformer (PDB ID 6V88). Dimer subunits are colored in green or magenta. A 2-fold axis of rotational symmetry lies vertically between the subunits. (D) Ribbon representation of a single $\operatorname{Skp} 1 \Delta \Delta$, with the residues contributing to intermolecular contacts $(<5 \AA)$ shown in green with stick representations of their side chains. (E) Surface representation of the $\operatorname{Skp} 1 \Delta \Delta$ dimer is shown with the rear subunit colored in green and red, and the front in transparent gray. Red shading represents the homodimer contact region. (F) Surface representation of a hypothetical Skp $1 \Delta \Delta /$ F-box heterodimer model, generated by substitution of a single $\operatorname{Skp} 1 \Delta \Delta$ subunit for $\operatorname{Skp} 1$ in a human Skp1/FBXW7 complex (PDB ID 5V4B). Coloration is as in E, with FBXW7 residues 2263-2355 in gray.

Figure 3. Computational scanning mutagenesis of the $\operatorname{Skp} 1 \Delta \Delta$ homodimer interface. (A) Alanine-scanning mutagenesis using Rosetta. Changes in binding free energy upon replacement with alanine are shown according to the interface residue positions. (B) Skp1 dimer protein-protein interface. Residues with the highest binding free energy change (Phe97 and Ile123) are emphasized in stick representation and in red; other mutated residues are in blue. See panel C for color code explanation. (C) Heatmap of the changes in binding free energy upon all amino acid substitutions. Effects of amino acid replacements are shown for each interface position. The colors represent the changes in the binding free energy of the dimer (interface $\Delta \Delta \mathrm{G}$ score). Values greater than one (warmer colors) indicate destabilizing mutations, and values less than one (colder colors) imply stabilizing mutation. ${ }^{28}$ Compare with effects on the monomer state (Fig. S7).

Figure 4. Skp1 $\triangle \mathrm{F} 97 \mathrm{E}$ is a stable and functional monomer in solution. (A) $c(s)$ distributions of $100 \mu \mathrm{M}$ Skp1 $\Delta$ or Skp1 $\Delta$ F97E are shown in cyan and black, respectively. (B) ${ }^{1} \mathrm{H} /{ }^{15} \mathrm{~N}-\mathrm{HSQC}$ of $100 \mu \mathrm{M}$ Skp1 $\Delta \mathrm{F} 97 \mathrm{E}$ at $900 \mathrm{MHz}$ and $35^{\circ} \mathrm{C}$, with a $4 \mathrm{~h}$ collection time. The $500 \mu \mathrm{M}$ spectrum (not shown) was indistinguishable. $(\mathrm{C}, \mathrm{D}) \mathrm{Skp} 1 \Delta \mathrm{F} 97 \mathrm{E}$ binds the model F-box protein Fbs1. His ${ }_{6} \mathrm{Fbs} 1(1.5 \mu \mathrm{M})$ and an estimated $2.25 \mu \mathrm{M}$ Skp1 $\Delta$ (C) or Skp1 $\Delta$ (F97E) (D) were analyzed on a Superdex 200 gel filtration column. Elution was monitored by $A_{280}$, which favors detection of Fbs1 relative to Skp1 because of its higher extinction coefficient. 
bioRxiv preprint doi: https://doi.org/10.1101/764126; this version posted January 26, 2020. The copyright holder for this preprint (which was not certified by peer review) is the author/funder, who has granted bioRxiv a license to display the preprint in perpetuity. It is made available under aCC-BY-NC-ND 4.0 International license.

\section{Figure 1}
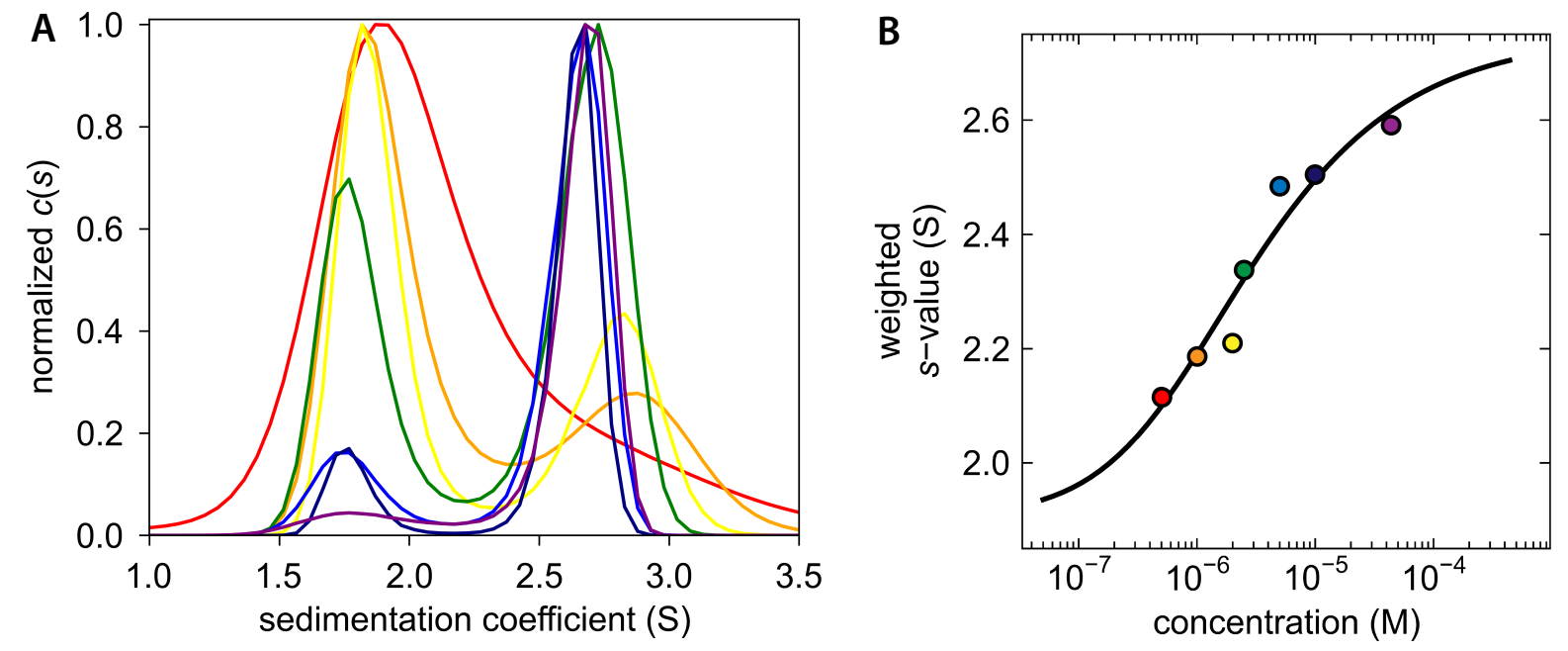
bioRxiv preprint doi: https://doi.org/10.1101/764126; this version posted January 26, 2020. The copyright holder for this preprint (which was not certified by peer review) is the author/funder, who has granted bioRxiv a license to display the preprint in perpetuity. It is made available under aCC-BY-NC-ND 4.0 International license.

\section{Figure 2}

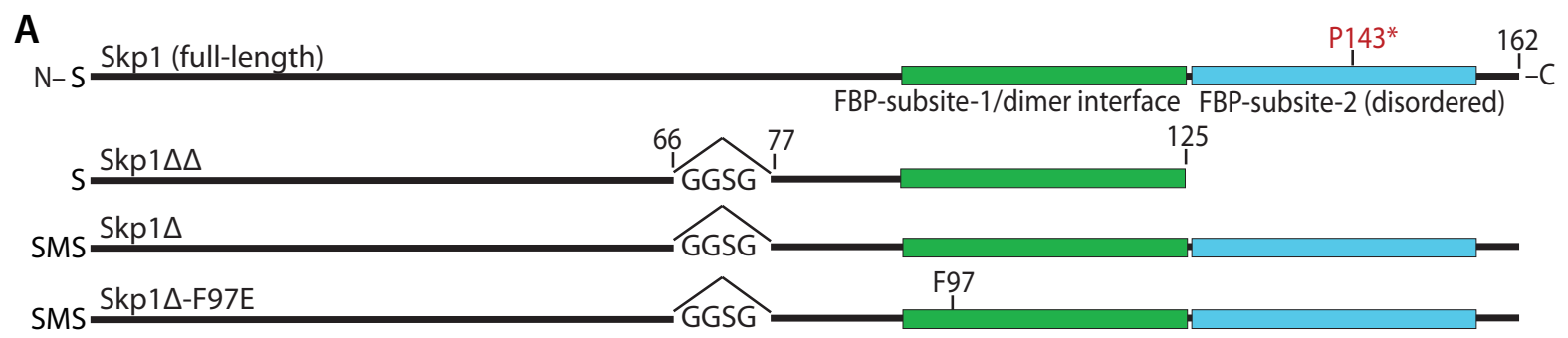

B

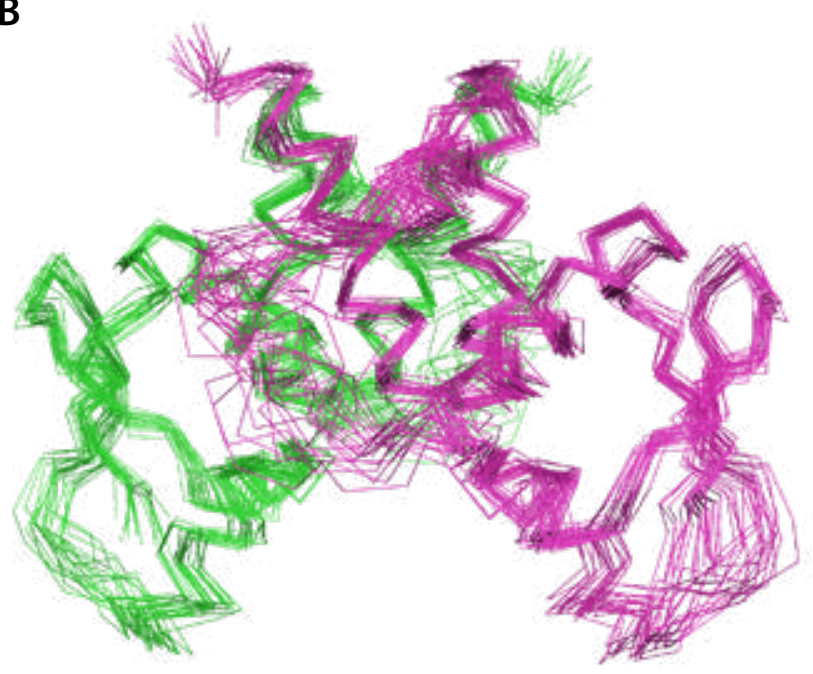

D

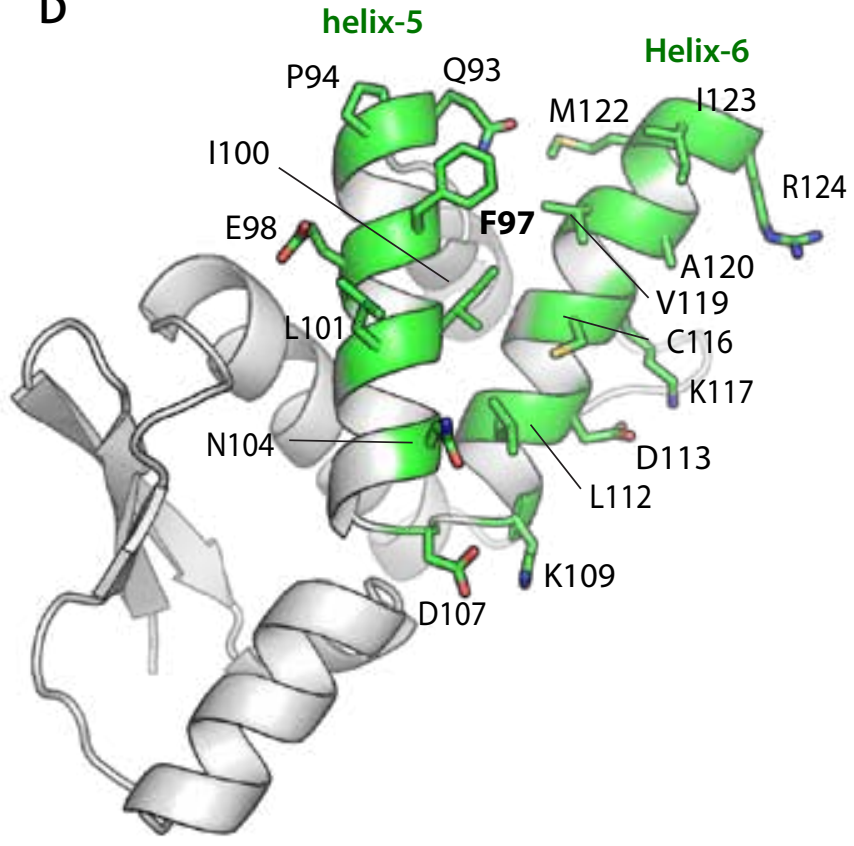

C

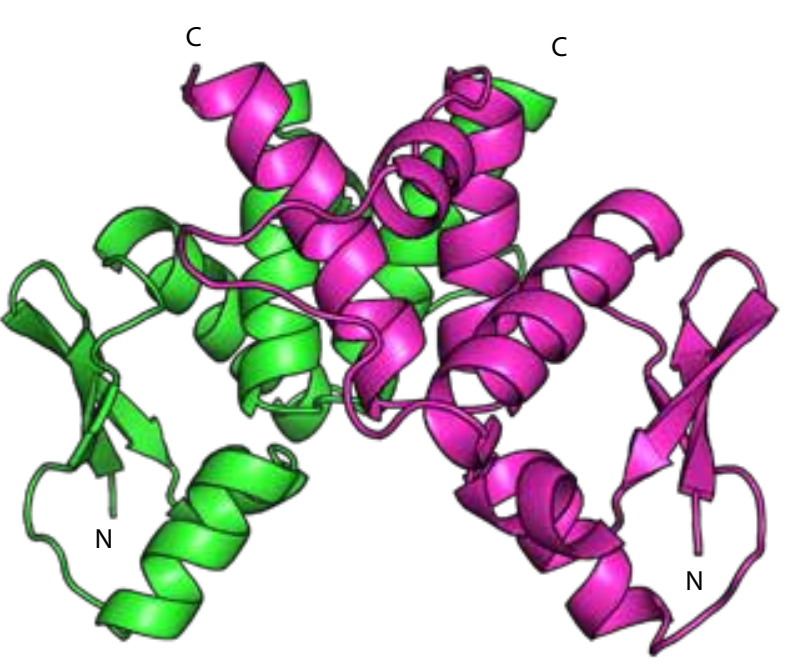

E
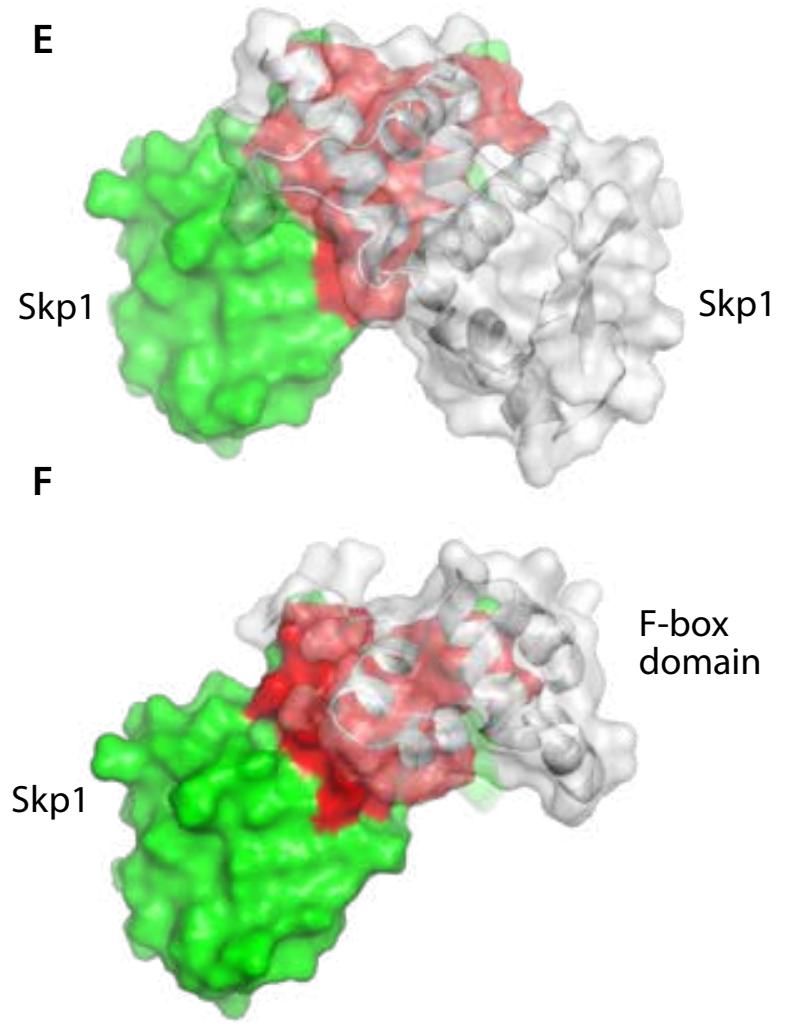


\section{Figure 3}
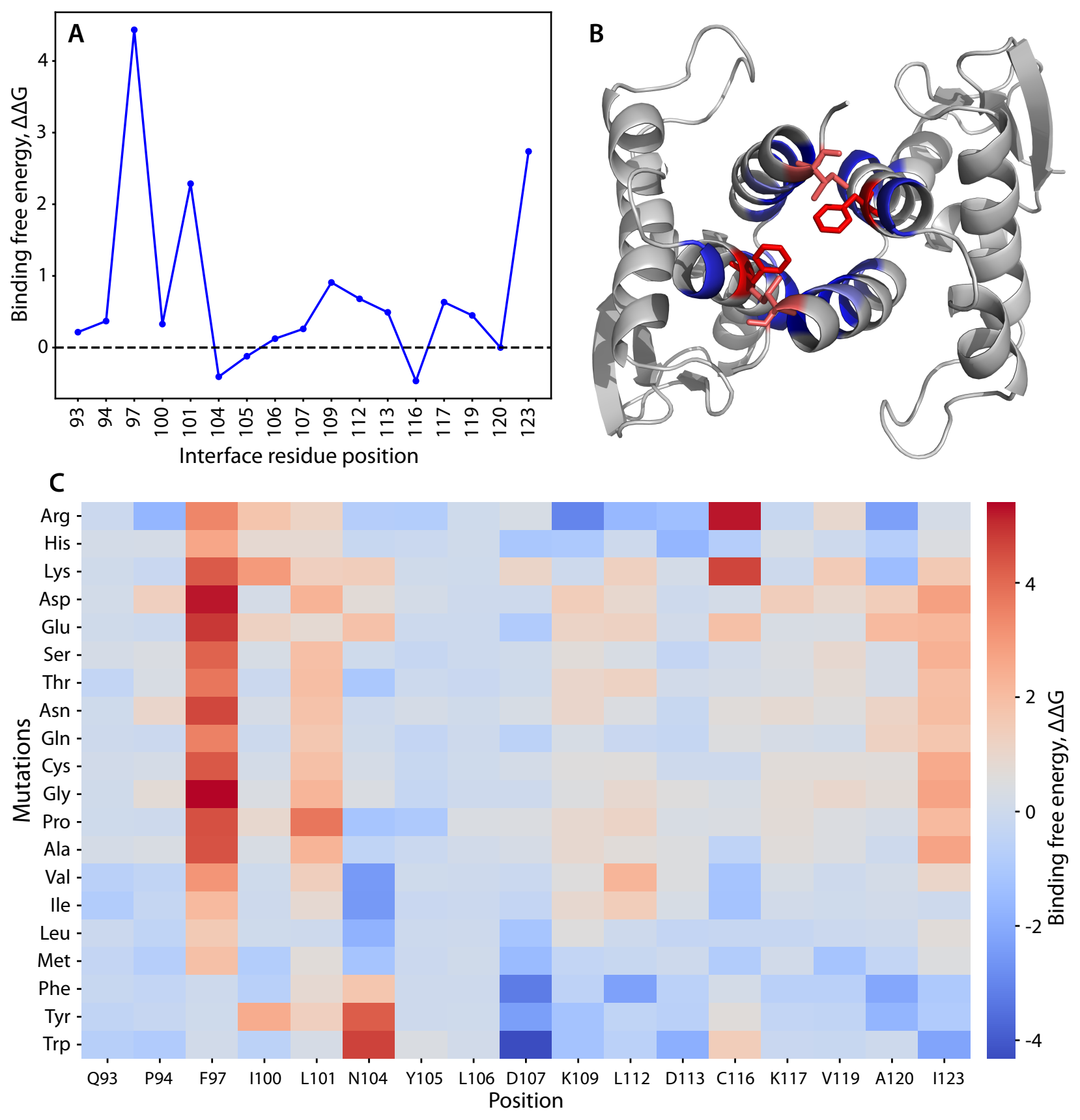


\section{Figure 4}
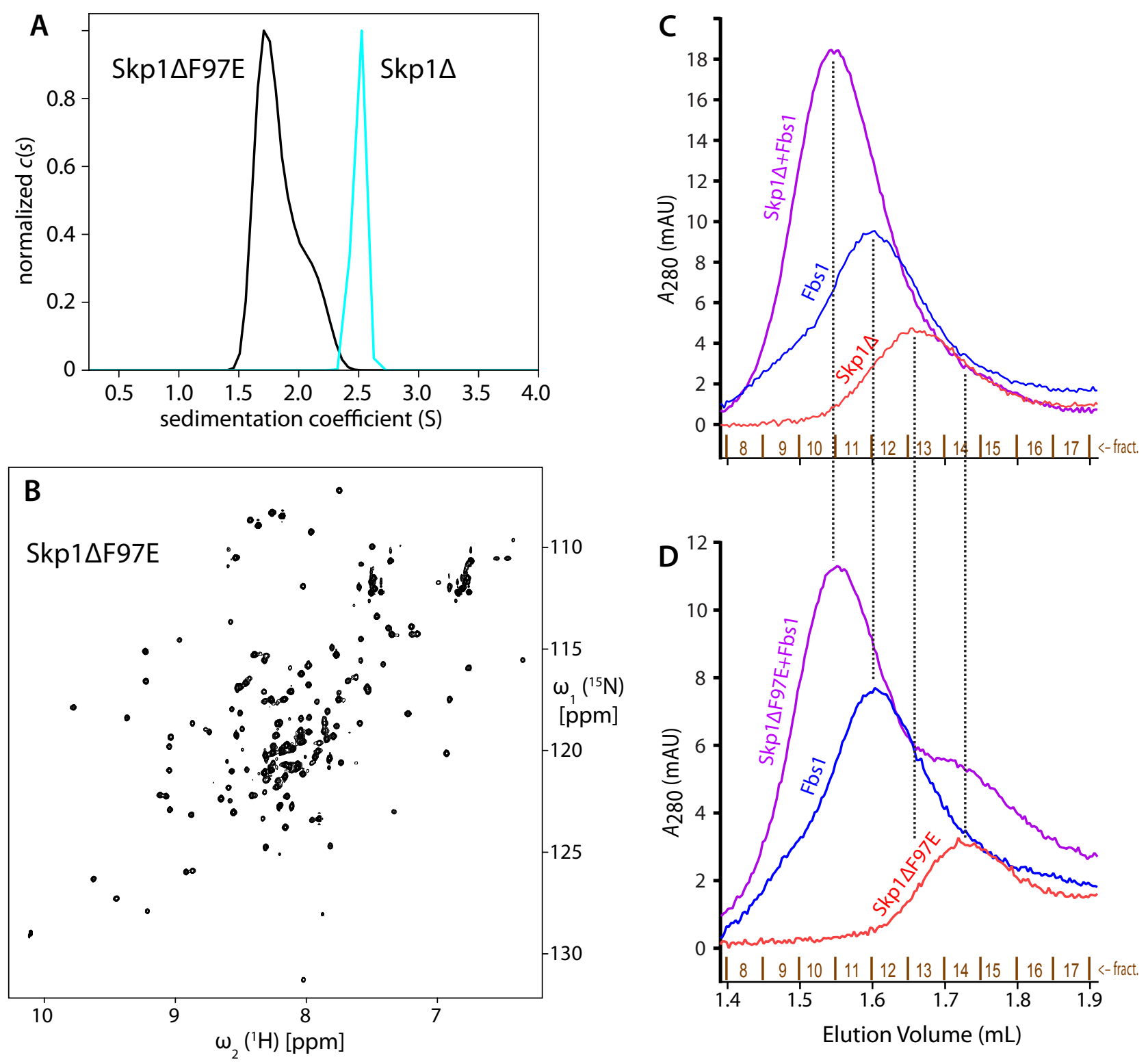